\title{
Quartz Crystal Microbalance Detection of DNA Single-base Mutation Based on Monobase-coded Cadmium Tellurium Nanoprobe
}

\author{
Yuqin Zhang, Fanbo Lin, Youyu Zhang, ${ }^{\dagger}$ Haitao Li, ${ }^{\dagger}$ Yue Zeng, Hao Tang, and Shouzhuo Yao \\ Key Laboratory of Chemical Biology and Traditional Chinese Medicine Research (Ministry of Education), \\ College of Chemistry and Chemical Engineering, Hunan Normal University, Changsha 410081, P. R. China
}

\begin{abstract}
A new method for the detection of point mutation in DNA based on the monobase-coded cadmium tellurium nanoprobes and the quartz crystal microbalance (QCM) technique was reported. A point mutation (single-base, adenine, thymine, cytosine, and guanine, namely, A, T, C and G, mutation in DNA strand, respectively) DNA QCM sensor was fabricated by immobilizing single-base mutation DNA modified magnetic beads onto the electrode surface with an external magnetic field near the electrode. The DNA-modified magnetic beads were obtained from the biotin-avidin affinity reaction of biotinylated DNA and streptavidin-functionalized core/shell $\mathrm{Fe}_{3} \mathrm{O}_{4} / \mathrm{Au}$ magnetic nanoparticles, followed by a DNA hybridization reaction. Single-base coded CdTe nanoprobes (A-CdTe, T-CdTe, C-CdTe and G-CdTe, respectively) were used as the detection probes. The mutation site in DNA was distinguished by detecting the decreases of the resonance frequency of the piezoelectric quartz crystal when the coded nanoprobe was added to the test system. This proposed detection strategy for point mutation in DNA is proved to be sensitive, simple, repeatable and low-cost, consequently, it has a great potential for single nucleotide polymorphism (SNP) detection.
\end{abstract}

(Received August 6, 2011; Accepted October 4, 2011; Published December 10, 2011)

\section{Introduction}

Single nucleotide polymorphisms (SNPs) are point mutations that are the most abundant forms of sequence variations between individuals and occur at a frequency of about one per $500-1000 \mathrm{bp}$ in human genome. SNPs are always closely correlative with susceptibility to various pathogenic and genetic diseases. ${ }^{1}$ As is well known, the transmission of the genetic code relies entirely on the specific pairings of adenine $(\mathrm{A})$ with thymine $(\mathrm{T})$, and cytosine $(\mathrm{C})$ with guanine $(\mathrm{G}) .^{2}$ A base change in the somatic cells may cause base-pair mismatch, which could lead to the tremendous transformation of a genetic code. ${ }^{3}$ For SNPs detection, approaches with high sensitivity, specificity, and reproducibility are necessary. In the past decades, there has been increasing interest in the development of biosensors for nucleic acid analysis and SNPs detection. ${ }^{4-7}$

A microgravimetric quartz crystal microbalance (QCM) is a particularly attractive device for DNA sensing. ${ }^{8,9}$ It allows the real-time measuring of DNA binding and hybridization at subnanogram level. Its potential application for the detection of specific DNA sequences has been demonstrated recently. ${ }^{10-12}$ Willner and his coworkers described two different experiment systems with QCM for the amplified detection of a single-base mismatch in DNA. One was based on the polymerase I-induced coupling of a biotinylated base complementary to the mutation site $^{13}$ and the other was based on the catalyzed deposition of gold on Au-nanoparticles. ${ }^{14}$ Zhou's group ${ }^{15}$ reported a novel

† To whom correspondence should be addressed.

E-mail: zhangyy@hunnu.edu.cn; haitao-li@hunnu.edu.cn microgravimetric technique for gene detection in which a sandwich-type ternary complex consisting of an oligodeoxynucleotide (ODN) was immobilized on a QCM electrode. Furlong's group ${ }^{16}$ employed a commercially available $27 \mathrm{MHz}$ QCM to in-situ investigate the binding of complementary and non-complementary 21-mer DNA oligonucleotides in solution. Most of these DNA biosensors were fabricated by covalent binding nucleic acids on the transducer surfaces. However, laborious and time-consuming efforts and relatively high costs have limited the applications of these biosensors. The chemical reactions between the nucleic acids and the transducer surfaces may change some physical properties of the transducers, and may also alter the biological properties of the nucleic acids. Thus, researchers hope to develop simple immobilization methods of DNA on transducer surfaces.

Recently, nanomaterials have attracted a great deal of attention because of their biological applications. Magnetic nanoparticles have many advantages in magnetic separation. ${ }^{17-20}$ Semiconductor nanoparticles, e.g., $\mathrm{CdS}$ and $\mathrm{CdTe}$, have been used as fluorescence probes for bioanalysis. The present study reports a novel method for DNA point mutation detection by the hybridization of a single-base-coded CdTe nanoparticle probe with the target DNA chain attached on $\mathrm{Fe}_{3} \mathrm{O}_{4} / \mathrm{Au}$ core/shell nanocomposites. In this work, core/shell $\mathrm{Fe}_{3} \mathrm{O}_{4} / \mathrm{Au}$ magnetic nanoparticles are used for separation and DNA immobilization. Semiconducting CdTe nanoparticles are modified with different single nucleotides to obtain single-base coded nanoprobes (A-CdTe, T-CdTe, G-CdTe and C-CdTe, respectively). The DNA-modified magnetic beads are immobilized on the electrode surface via an external magnetic field. This immobilization protocol avoids the direct chemical reaction between the nucleic 


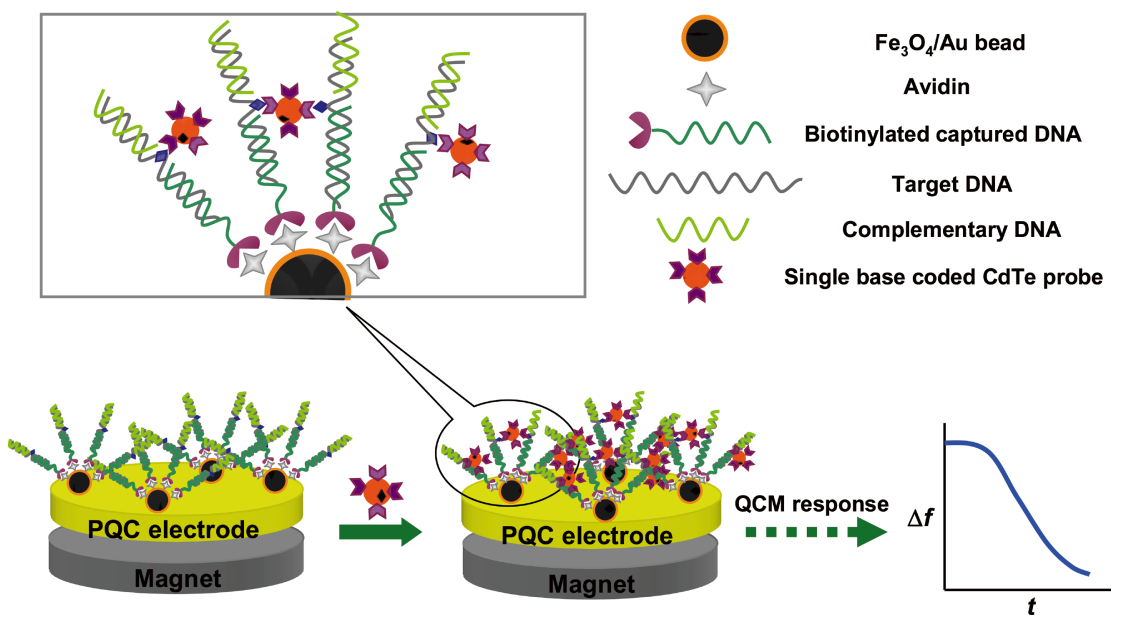

Fig. 1 An illustration for DNA immobilization and point mutation detection.

acid and the transducer surfaces, and improves the reproducibility of the Au-quartz piezoelectric crystal. Figure 1 outlines the fabrication process of the DNA sensor. Biotinylated DNA, target DNA and complementary DNA are sequentially modified onto the surface of magnetic beads through the biotin-avidin affinity reaction and the DNA hybridization reaction. Then the DNA-avidin- $\mathrm{Au} / \mathrm{Fe}_{3} \mathrm{O}_{4}$ complexes are immobilized onto the gold electrode surface by an external magnetic field. The following addition of the single-base coded CdTe nanoprobe leads to specific binding to different mismatched sites via base-pairing, and causes the resonance frequency of the piezoelectric crystal to shift. Thus the mutation points in DNA strands could be identified with this proposed simple, rapid, and harmless method. The sensor could be regenerated and only a small volume of sample is required.

\section{Experimental}

\section{Reagents}

Tellurium powder $(99.0 \%), \mathrm{CdCl}_{2} \cdot 2.5 \mathrm{H}_{2} \mathrm{O}(99.0 \%)$, L-cysteine (98.5\%), $\mathrm{NaBH}_{4}(98.0 \%)$ and tri(hydroxymethyl)aminomethane (Tris) were purchased from Shanghai Chemical Reagents Co. 1-Ethyl-3-(3-dimethyllaminopropyl)carbodiimide (EDC) was obtained from Sigma Co. Chloroauric acid tetrahydrate was purchased from Sinopharm Chemical Reagent Co., Ltd. Adenosine 5'-monophosphate, cytidine 5'-monophosphate, guanosine $5^{\prime}$-monophosphate, thymidine $5^{\prime}$-monophosphate and avidin were purchased from Shanghai Sangon Biological Engineering Technology \& Services Co., Ltd. All chemicals were used without additional purification. The mixture of $750 \mathrm{mM} \mathrm{NaCl}$ and $15 \mathrm{mM}$ sodium citrate (pH 7.4) was used as the buffer for hybridization. Tris- $\mathrm{HCl}$ buffer $(\mathrm{pH} 7.4,50 \mathrm{mM}$ Tris, $100 \mathrm{mM} \mathrm{NaCl}, 5 \mathrm{mM} \mathrm{KCl}, 1 \mathrm{mM} \mathrm{MgCl}$, $5 \mathrm{mM} \mathrm{CaCl}$ ) was used as the washing buffer. Milli-Q ultrapure water (Millipore, $\geq 18 \mathrm{M} \Omega \mathrm{cm}^{-1}$ ) was used throughout the experiments.

The synthetic oligonucleotides were purchased from Shanghai Sangon Biological Engineering Technology \& Services Co., Ltd. and had the following sequences.

Biotinylated strand: 5'-GTATCGCCGCGAGGGATATCCAGCTGCGGTAAACGTCATCG-Bio-3'. - -SH strand: 5'-GTATCGCCGCGAGGGATATCCAGCTGCGGTAAACGTCATCG-SH-3'. Target strand: 1, 5'-CGATGACGTTTACCGCAGCTGGATATC-
CCTCGCGGCGATACAGCGGCTCG; 2, 5'-CGATGACGTTTACCGCAGCTGGATATCCCTCGCGGCGATACTGCGGCCTCG; 3, 5'-CGATGACGTTTACCGCAGCTGGATATCCCTCGCGGCGATACCGCGGCCTCG; 4, 5'-CGATGACGTTTACCGCAGCTGGATATCCCTCGCGGCGATACGGCGGCCTCG. Complementary strand: 1, 5'-CGAGGCCGCT; 2, 5'-CGAGGCCGCA; 3, 5'-CGAGGCCGCG; 4, 5'-CG AGGCCGCC; 5, 5' CGAGGCCGC; 6, 5'-FAM-( $\left.\mathrm{CH}_{2}\right)_{6}$-CGAGGCCGC.

\section{Apparatus}

Microgravimetric quartz crystal microbalance experiments were performed with a research quartz crystal microbalance (RQCM, Maxtek Inc., USA). AT-cut $9 \mathrm{MHz}$ piezoelectric quartz crystals ( $12.5 \mathrm{~mm}$ in diameter) were used. There are two gold electrodes $\left(6.5 \mathrm{~mm}\right.$ in diameter, about $0.29 \mathrm{~cm}^{2}$ in area) on each side. The IR spectra were collected on a Nicolet Nexus 670 FTIR spectrometer (Nicolet Instrument Co., Madison, WI) controlled by the Ominic software in the transmission mode, and the samples were prepared as $\mathrm{KBr}$ pellets. Atomic force microscopy (AFM) images were obtained on a PicoPlus AFM (Molecular Imaging Co., USA).

\section{Preparation of CdTe nanoparticles}

The preparation of CdTe nanoparticles by the hydrothermal route has been described in detail elsewhere. ${ }^{21}$ Briefly, $18.97 \mathrm{mg}$ of sodium borohydride and $31.90 \mathrm{mg}$ of tellurium powder with a molar ratio of 2:1 were added into a small flask, then, $5 \mathrm{~mL}$ of ultrapure water was added. The reacting system was cooled by ice in the dark. After the reaction continued for approximately $10 \mathrm{~h}$, the black tellurium powder disappeared and sodium tetraborate, a kind of white precipitation, appeared on the bottom of the flask instead. The resulting NaHTe in clear supernatant was separated and used for the preparation of CdTe nanoparticles.

The CdTe colloidal solution was prepared from $\mathrm{Cd}^{2+}$ and NaHTe solution in the presence of L-cysteine, which served as the stabilizing agent; $18.97 \mathrm{mg}$ of $\mathrm{CdCl}_{2} \cdot 5 \mathrm{H}_{2} \mathrm{O}$ and $72.95 \mathrm{mg}$ of cysteine were dissolved in $50 \mathrm{~mL}$ of pure water. The $\mathrm{pH}$ value was adjusted to 11.2 using $1 \mathrm{M} \mathrm{NaOH}$ and the mixture was reacted for approximately $30 \mathrm{~min}$. The mix solution was refluxed for $8 \mathrm{~h}$ at $100^{\circ} \mathrm{C}$. The molar ratio of $\mathrm{Cd}^{2+} / \mathrm{thiols}_{\mathrm{s}} / \mathrm{HTe}^{-}$ was fixed at 1:2.4:0.5. 


\section{Preparation of single base coded CdTe nanoprobes}

Single-base-coded CdTe probes, such as C-CdTe, G-CdTe, T-CdTe and A-CdTe, were obtained by immobilizing the corresponding single nucleotide onto the L-cysteine-capped water-soluble $\mathrm{CdTe}$ nanoparticles through phosphoramidite bonds formed by the $5^{\prime}$ phosphategroup of the single nucleotide with the free amino groups on the CdTe nanoparticle surface. ${ }^{22}$ For example, adenine coded CdTe nanoprobes were prepared by the following process: $200 \mu \mathrm{L}$ of adenine nucleotide hybridization buffer solution $(10 \mathrm{mM})$ was mixed with $200 \mu \mathrm{L}$ EDC aqueous solution $(50 \mathrm{mM})$ and then added to $10 \mathrm{~mL}$ of the L-cysteine-capped CdTe solution; the mixture was then shaken for $1 \mathrm{~h}$. The reaction mixture was dialyzed with a 50-K dialysis membrane against $1 \mathrm{~L}$ of hybridization buffer $(\times 10$ dilution of hybridization buffer) for $17 \mathrm{~h}$ to remove excess adenine nucleotide (the dialysis buffer was changed 10 times within the dialysis). Thymine-, guanine- and cytosine-coded CdTe nanoprobes were obtained with the same method.

\section{Preparation of Au-coated magnetic beads}

A 2.900 -g portion of $\mathrm{FeCl}_{3} \cdot 6 \mathrm{H}_{2} \mathrm{O}$ was dissolved in $200 \mathrm{~mL}$ of aqueous solution containing $20 \mu \mathrm{L}$ of concentrated $\mathrm{HCl}$. Then $1.117 \mathrm{~g} \mathrm{FeCl}_{2} \cdot 4 \mathrm{H}_{2} \mathrm{O}$ was added into the mixed solution. A $100-\mathrm{mL}$ volume of $1.5 \mathrm{M} \mathrm{NaOH}$ solution was dropwise added into the mixture with vigorous stirring under nitrogen atmosphere. A black precipitate formed immediately. The precipitate was separated via magnetic decantation and washed with ultrapure water, and then resuspended in $250 \mathrm{~mL}$ of ultrapure water. Subsequently, $4 \mathrm{~mL}$ of $4 \% \mathrm{HAuCl}_{4}$ aqueous solution and an excess of $0.1 \mathrm{M} \mathrm{NH}_{2} \mathrm{OH} \cdot \mathrm{HCl}$ were slowly added into the suspension (with at least $10 \mathrm{~min}$ between the two additions). The reaction was allowed to continue for $1 \mathrm{~h}$ to produce Au-coated magnetic nanoparticles. The resultant suspended precipitate was separated with a magnet, and washed with ultrapure water for 4 times to remove nonmagnetic particles.

Preparation of single base mutation DNA modified-magnetic beads

Magnetic nanoparticles were functionalized by avidin. One-half milligram of $\mathrm{Au} / \mathrm{Fe}_{3} \mathrm{O}_{4}$ nanoparticles was suspended in $500 \mu \mathrm{L}$ of hybridization buffer and the mixture was stirred for 30 min with an ultrasonator. A $100-\mu \mathrm{g}$ portion of avidin was added to the nanoparticle suspension. After $6 \mathrm{~h}$ of incubation, the avidin-modified magnetic nanoparticles were isolated by magnetic separation in order to remove the excessive avidin in the solution. Avidin-modified beads were washed twice with $500 \mu \mathrm{L}$ of Tris- $\mathrm{HCl}$ buffer. Then the avidin-modified magnetic beads were mixed with $500 \mu \mathrm{L}$ of hybridization buffer and $4 \mu \mathrm{L}$ of biotinylated single strand DNA $(100 \mu \mathrm{M})$. The mixture was incubated for $1 \mathrm{~h}$ at $37^{\circ} \mathrm{C}$ with gentle shaking. ${ }^{23}$ The resultant single strand DNA-avidin- $\mathrm{Au} / \mathrm{Fe}_{3} \mathrm{O}_{4}$ nanoparticles were resuspended in $500 \mu \mathrm{L}$ of hybridization buffer after magnetic separation, and different target DNAs or complementary DNA were added to the reaction mixture. After each incubation and washing, the corresponding magnetic beads modified with single base mutation DNA were obtained.

The surface coverage of the point mutation DNA strand on the $\mathrm{Au} / \mathrm{Fe}_{3} \mathrm{O}_{4}$ nanoparticle was estimated with the following procedure. Fluorescein-labeled oligonucleotides (complementary strand 6) were used to hybridize with the single strand DNA-avidin- $\mathrm{Au} / \mathrm{Fe}_{3} \mathrm{O}_{4}$ nanoparticles instead of other complementary DNA. Then the isolated resultant nanoparticles was resuspended and heated at $100^{\circ} \mathrm{C}$ for $5 \mathrm{~min}$ to dissociate the doubled DNA stands. After magnetic separation, the fluorescence of the supernatant solution was detected and the concentration of fluorescein-labeled oligonucleotides was obtained. Consequently, the number of the immobilized DNA on the $\mathrm{Au} / \mathrm{Fe}_{3} \mathrm{O}_{4}$ nanoparticle surface could be calculated.

\section{Detection of single-base mutation in DNA}

The QCM was mounted on the detection cell. One side of the quartz crystal was in contact with solution and served as the work electrode. The other side of the QCM was exposed to air and placed close to a magnet. The magnet was used to produce an external magnetic field to immobilize DNA modified $\mathrm{Fe}_{3} \mathrm{O}_{4} / \mathrm{Au}$ core/shell nanoparticles onto the surface of QCM. To remove possible surface contaminants, we cleaned the work electrode with fresh Piranha solution $\left(\mathrm{H}_{2} \mathrm{SO}_{4} / \mathrm{H}_{2} \mathrm{O}_{2}, 3: 1\right.$, v/v), followed by rinsing with ultrapure water after each hybridization experiment. A $800-\mu \mathrm{L}$ volume of hybridization buffer solution was added to the detection cell, and the clean QCM work electrode was immersed in buffer solution. The frequencies were continuously recorded using a research quartz crystal microbalance (RQCM, Maxtek Inc., USA) controlled by Maxtek RQCM software. A $40-\mu \mathrm{L}$ volume of single base mutation DNA modified magnetic beads suspension was added in buffer solution after stable frequency responses of the PQC electrode were obtained. With the addition of the suspension, about $600 \mathrm{~Hz}$ sharp decreases in the frequency of the quartz crystal were observed. Ten minutes later, the magnetic beads were entirely attached to the Au electrode surface through an external magnetic field in the vicinity of the solution. After a stable resonance frequency was achieved, $500 \mu \mathrm{L}$ of single nucleotide modified CdTe probes was injected into the detection cell, and the in-situ QCM frequency shift was monitored. All detection experiments were performed at $25^{\circ} \mathrm{C}$.

\section{Results and Discussion}

Characterization of L-cysteine-modified CdTe nanoparticles

L-Cysteine-modified CdTe nanoparticles were characterized by FT-IR and AFM. The results are shown in Fig. 2. The IR spectra of L-cysteine and L-cysteine-modified CdTe nanoparticles are shown in Figs. 2A and 2B, respectively. The absorption peaks at 1587, 2079, 2549, 2967, and $3176 \mathrm{~cm}^{-1}$ in Fig. $2 \mathrm{~A}$ are related to the characteristic IR absorption of L-cysteine. ${ }^{24}$ In Fig. 2B, absorption peaks at 3412, 2920 and $1589 \mathrm{~cm}^{-1}$ are observed, and the characteristic IR absorption at $2549 \mathrm{~cm}^{-1}$ that is related to the sulfhydryl group of L-cysteine disappeared in Fig. 2B, this indicated that L-cysteine molecules were successfully immobilized onto the CdTe nanoparticles. The CdTe nanoparticles were further characterized by atomic force microscopy (AFM). As shown in Fig. 2C, the CdTe nanoparticles are of uniformly spherical shapes. The particles have $30 \mathrm{~nm}$ of average diameter and $20 \mathrm{~nm}$ of most probable diameter, respectively (Fig. 2D).

\section{Characterization of the $\mathrm{Au} / \mathrm{Fe}_{3} \mathrm{O}_{4}$ nanoparticles}

The $\mathrm{Au} / \mathrm{Fe}_{3} \mathrm{O}_{4}$ nanoparticles were investigated in detail with UV-vis, X-ray diffraction (XRD) and AFM. Figure 3A shows the UV-vis absorption spectra of $\mathrm{Au} / \mathrm{Fe}_{3} \mathrm{O}_{4}$ and $\mathrm{Fe}_{3} \mathrm{O}_{4}$ nanoparticles. The maximum UV-vis absorption peak of $\mathrm{Au} / \mathrm{Fe}_{3} \mathrm{O}_{4}$ nanoparticle appeared at $550 \mathrm{~nm}$, and no maximum absorption peak was observed in the case of $\mathrm{Fe}_{3} \mathrm{O}_{4}$ nanoparticles. The UV-vis absorption peak at $550 \mathrm{~nm}$ could be ascribed to the surface plasmon resonance of nanosized $\mathrm{Au}$, which suggested that gold nanoparticles were coated on $\mathrm{Fe}_{3} \mathrm{O}_{4}$. Figure 3B shows the X-ray diffraction (XRD) pattern of the $\mathrm{Au} / \mathrm{Fe}_{3} \mathrm{O}_{4}$ 

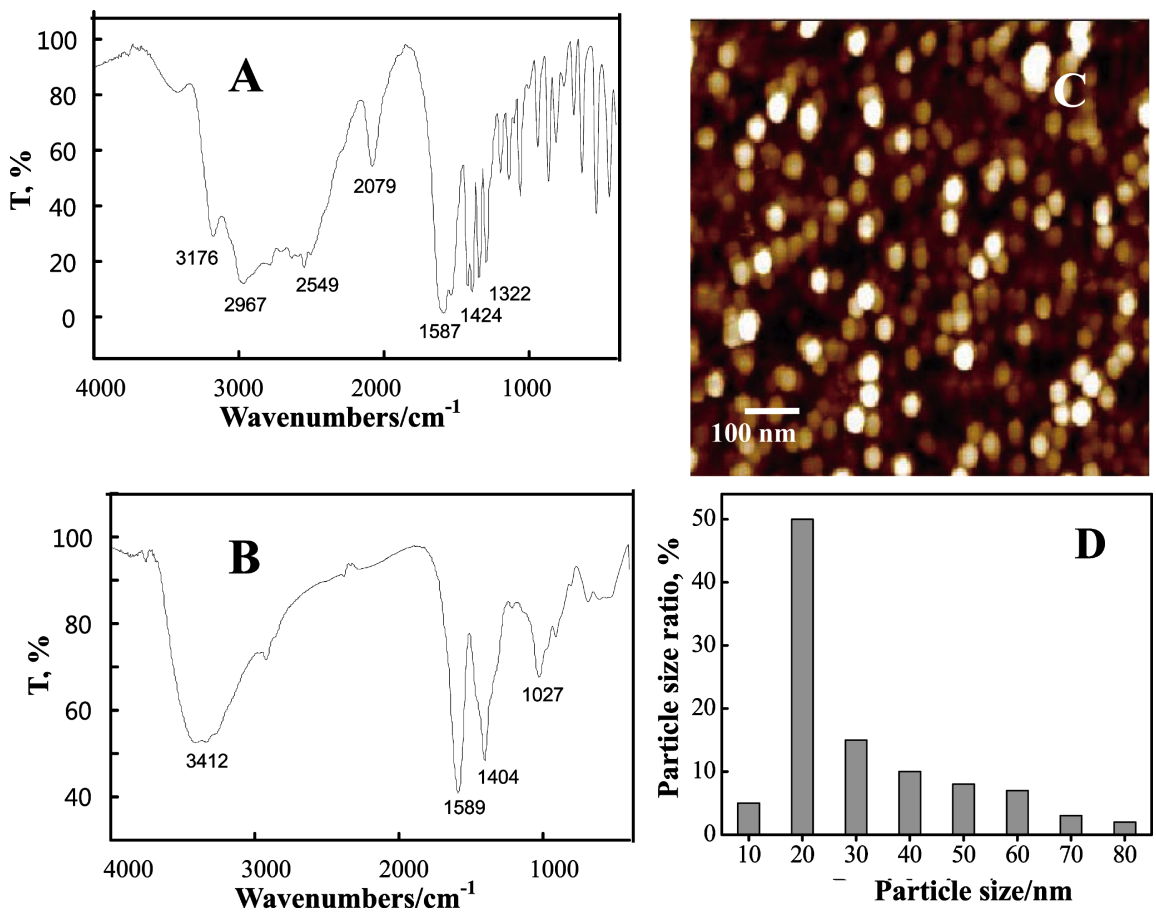

Fig. 2 IR spectra of L-cysteine (A) and L-cysteine-modified CdTe nanoparticles (B). AFM images of $\mathrm{CdTe}(\mathrm{C})$ and the size distribution of nanoparticles (D).
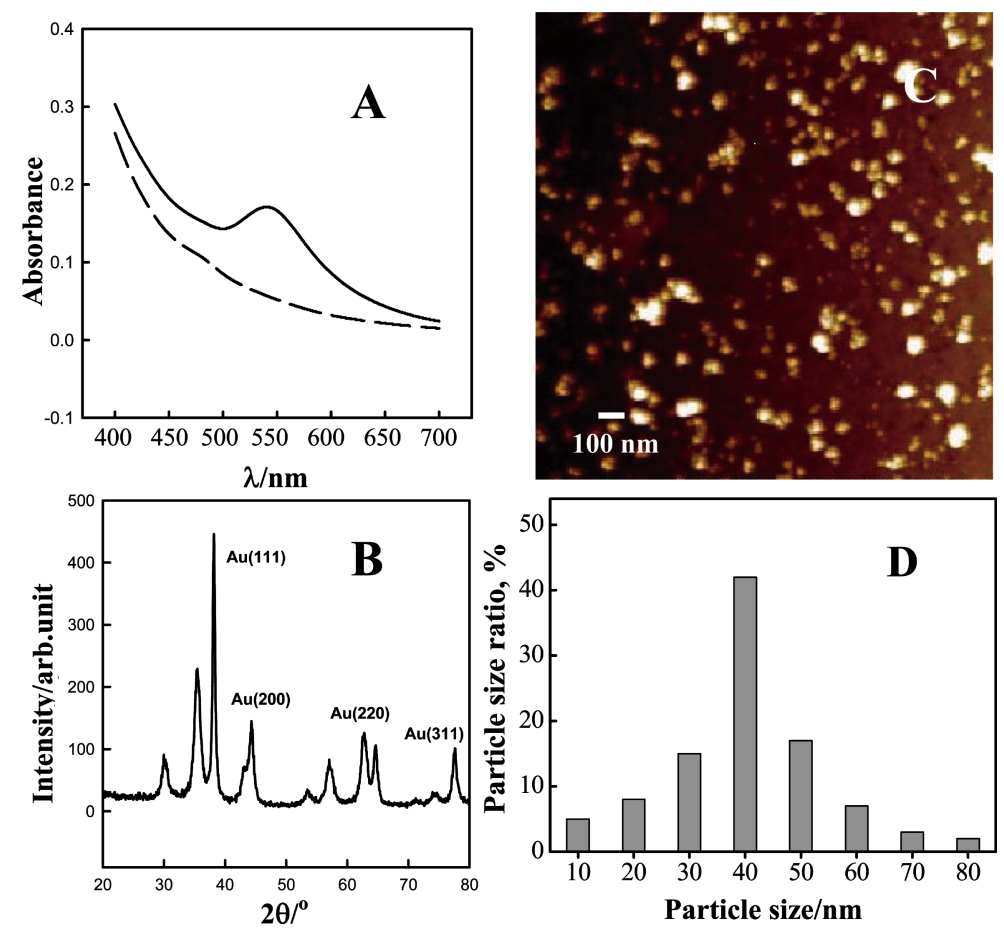

Fig. 3 (A) UV-vis absorption spectra of aqueous solution containing $\mathrm{Au} / \mathrm{Fe}_{3} \mathrm{O}_{4}$ core/shell nanoparticles (solid line) or $\mathrm{Fe}_{3} \mathrm{O}_{4}$ nanoparticles (dashed line), (B) XRD pattern of $\mathrm{Au} / \mathrm{Fe}_{3} \mathrm{O}_{4}$, (C) AFM images of $\mathrm{Au} / \mathrm{Fe}_{3} \mathrm{O}_{4}$ nanoparticles and (D) the size distribution of nanoparticles.

nanoparticles. The diffraction peaks related to $\mathrm{Au}\left(\begin{array}{lll}1 & 1 & 1\end{array}\right)$, $\operatorname{Au}(200), \operatorname{Au}(220)$, and $\operatorname{Au}(3 \quad 11)$ are clearly exhibited in the diffraction spectra, which confirmed that Au-coated $\mathrm{Fe}_{3} \mathrm{O}_{4}$ nanoparticles $\left(\mathrm{Au} / \mathrm{Fe}_{3} \mathrm{O}_{4}\right)$ were successfully prepared. As shown in Figs. 3C and 3D, the AFM images of the $\mathrm{Au} / \mathrm{Fe}_{3} \mathrm{O}_{4}$ nanoparticles reveal that the size distribution of the particles has monodisperse character to some extent and the particles have an average diameter of $40 \mathrm{~nm}$. It can be hypothesized that the Au shell grows by nucleating from small nanoparticles on the $\mathrm{Fe}_{3} \mathrm{O}_{4}$-core surface before it develops the shell structure. ${ }^{25}$ 
The surface coverage of point mutation DNA on $\mathrm{Au} / \mathrm{Fe}_{3} \mathrm{O}_{4}$ nanoparticle was estimated according to the results obtained from the AFM and fluorescence measurements. There are around 54 DNA strands on each $\mathrm{Au} / \mathrm{Fe}_{3} \mathrm{O}_{4}$ particle.

Quartz crystal microbalance detection of point mutation in DNA The point mutation DNA QCM sensor was fabricated by immobilizing point mutation DNA $\mathrm{Au} / \mathrm{Fe}_{3} \mathrm{O}_{4}$ nanoparticles on the surface of the QCM electrode. The mass of the functionalized $\mathrm{Au} / \mathrm{Fe}_{3} \mathrm{O}_{4}$ nanoparticles loaded on the electrode was controlled by monitoring the QCM resonance frequency shift. About $600 \mathrm{~Hz}$ QCM resonance frequency decrease was adopted, which corresponds to about $9.45 \times 10^{2} \mathrm{ng}$ functionalized $\mathrm{Au} / \mathrm{Fe}_{3} \mathrm{O}_{4}$ nanoparticles being loaded onto the QCM. The coverage of the nanoparticles on QCM surface was $3.259 \times 10^{-3} \mathrm{ng} / \mathrm{cm}^{2}$, which is equivalent to $1.88 \times 10^{10}$ nanoparticles per square centimeter (the result was estimated from the average diameter of $40 \mathrm{~nm}$ and the density of $\mathrm{Fe}_{3} \mathrm{O}_{4} 5.18 \mathrm{~g} / \mathrm{cm}^{3}$ ). The surface coverage of the point mutation DNA strands on the surface of QCM electrode was about $1.02 \times 10^{11}$ molecules per square centimeter. Single-base coded CdTe nanoprobes were added into the system and the resonance frequency responses were recorded in situ. In the control experiments, complete complementary DNA was used instead of single base mutation DNA. Figure 4 depicts the time-dependent QCM frequency responses during the hybridization of single nucleotide coded CdTe probes (T-CdTe, A-CdTe, G-CdTe and C-CdTe) with the single base vacant DNA. The curves labeled with " $b$ " in Fig. 4 clearly indicate that, when the single base loaded on the CdTe nanoparticles and the vacant site base at the target DNA form a complementary base pair, significant QCM resonance frequency decreases were observed during the hybridization. The frequency responses decreased about $84,123,90$ and $85 \mathrm{~Hz}$ for the hybridization of $\mathrm{T}, \mathrm{A}, \mathrm{G}$ and $\mathrm{C}$ coded CdTe nanoprobles with the target DNAs containing $\mathrm{A}, \mathrm{T}, \mathrm{C}$ and $\mathrm{G}$ base vacant site, respectively. According to Sauerbrey equation, ${ }^{26}$ the corresponding mass increase on QCM electrode surface was 133.1, 194.9, 142.6 and $134.8 \mathrm{ng}$, respectively. This indicated that the surface coverages of T, A, G and C coded CdTe nanoprobles on QCM DNA sensor are $460,670,490$ and $460\left(\mathrm{ng} / \mathrm{cm}^{2}\right)$, respectively. In the case of complementary DNA strand modified onto the QCM instead of DNA molecules with vacant site, only very small changes in the resonance frequency were observed (curves labeled with "a" in Fig. 4), which suggests that a small mass change may be caused by the nonspecific adsorption. These experimental facts indicated that the single-base vacant sites in DNA can be distinguished by the frequency change of QCM during the interaction of coded probe with the vacant sites. It is known that short DNA duplexes are rather unstable. If the binding ratio of the mutation DNA with single-base coded CdTe probe were $1: 1$, the configuration obtained from the hybridization of DNA molecules containing vacant base site with single-base coded CdTe probe would be unstable, and the frequency shift should be small. In fact, an obvious frequency change was observed, which suggests that the introducing of single base modified CdTe nanoproble resulted in an increase in mass on the crystal, and that strong interaction existed. Such experimental facts can be explained by the multiple reaction sites on one coded nanoprobe to bind multiple point mutation DNA strands on electrode surface, and thus the binding reaction is strong enough.

Contrast tests were therefore performed in order to further clarify the effects of non-specific adsorption. CdTe, C-CdTe and G-CdTe nanoprobes were used to hybridize with target DNA containing an A base vacant site, respectively. Only very small frequency changes were observed in all the cases (Fig. 5).
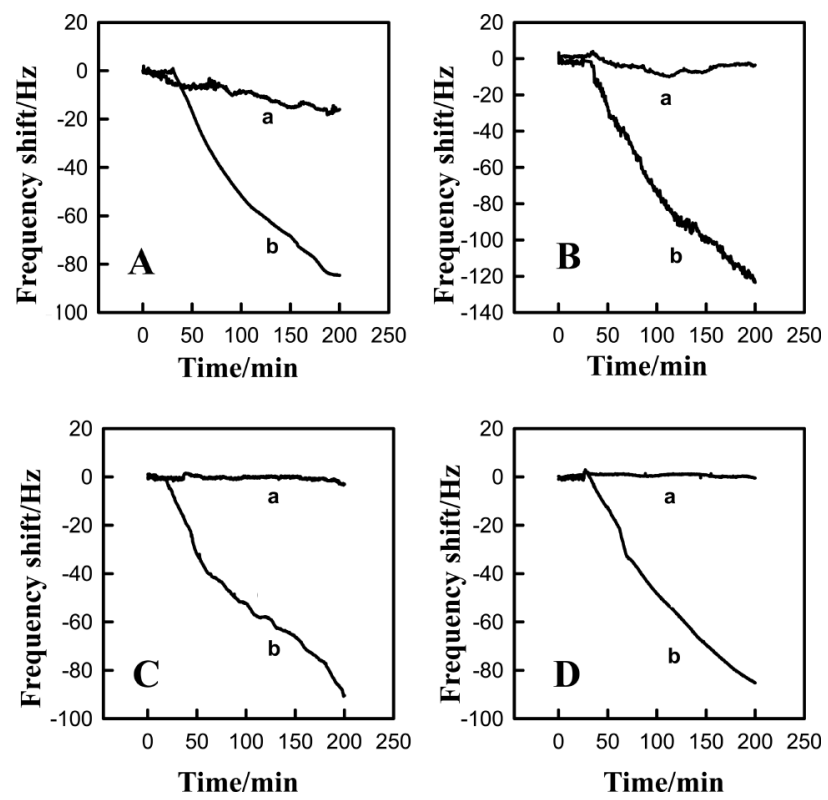

Fig. 4 QCM resonance frequency responses during the hybridization of single nucleotide coded CdTe probes (T-CdTe, A-CdTe, G-CdTe and C-CdTe) with the single base (A, T, C and G) vacant DNA. (A) Probes A-CdTe (a) and T-CdTe (b) were hybridized with A base vacant DNA, respectively, (B) probes A-CdTe (a) and T-CdTe (b) were hybridized with $\mathrm{T}$ base vacant DNA, respectively, (C) probes C-CdTe (a) and G-CdTe (b) were hybridized with $\mathrm{C}$ base vacant DNA, respectively, (D) probes C-CdTe (a) and G-CdTe (b) were hybridized with $\mathrm{G}$ base vacant DNA, respectively.

Such results are distinctly different from the case of T-CdTe probe (Fig. 4A). The difference suggests that the effects of non-specific adsorption could be neglected. Another contrast experiment was also performed by using a bare gold QCM electrode. Target DNA was directly self-assembled onto the surface of the electrode by the thiol group connected at the terminal end of DNA, instead of immobilizing to magnetic beads. The hybridization of single-base coded CdTe nanoprobes with the self-assembled DNA and the QCM resonance frequency responses detection were performed following the above-mentioned strategy. Then, $50 \mathrm{~Hz}$ frequency decrease was observed (shown in Fig. 6) during the hybridization of G-CdTe nanoprobes with the self-assembled target DNA containing $\mathrm{C}$ base vacant sites, which was less than the frequency response observed in the case of immobilizing target DNA onto magnetic nanoparticles (as shown in Fig. 4A). As shown in Fig. $6,17 \mathrm{~Hz}$ frequency decrease caused by the non-specific adsorption was observed when $\mathrm{C}$-CdTe probes were added to the system where self-assembled target DNA was employed. From the experiment mentioned above, we concluded that the proposed assay strategy for the detection of point mutation in DNA strands was experimentally demonstrated to be reliable and relatively simple, and the magnetic nanoparticles contributed to the amplification of the detection signal and the reduction of the signal to noise ratio.

By using the method mentioned above, one can easily detect single-base vacant sites in DNA. In order to further verify the efficiency of the developed method for mutation sites detection, a DNA biosensor with a single base mismatch site was fabricated, and a single-base coded CdTe nanoprobe was used to examine the single base mismatch site in the DNA strand. Figure 7 shows the QCM responses during the hybridization of 


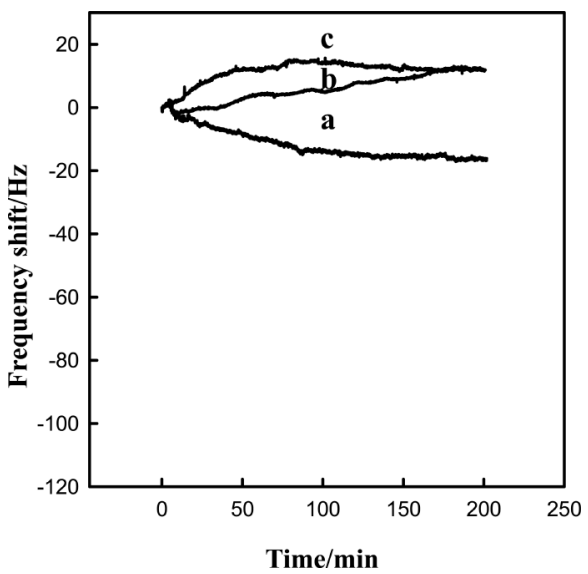

Fig. 5 Frequency change versus time during the hybridization of single nucleotide modified CdTe probes with the single base vacant in target DNA. Curves a, b and c represent cases where probes CdTe, C-CdTe and G-CdTe were added to A base vacant system, respectively.

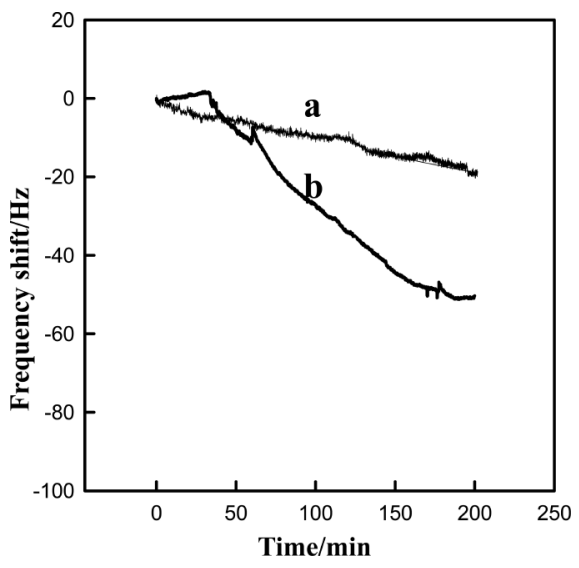

Fig. 6 Frequency change versus time during the hybridization of probes C-CdTe (a) and G-CdTe (b) with C base vacant in target DNA on gold electrode, respectively. The target DNA was immobilized on the gold electrode in the following procedure: Thiolated ssDNA ( $\mathrm{SH}$ strand) was firstly self-assembled on the gold electrode, and then sequentially hybridized with target strand 3 and complementary strand 5.

single base modified CdTe nanoproble with monobase mismatch site in target DNA. The point mutation involved a T-G mismatch (Fig. 7A) and an A-C mismatch, respectively (Fig. 7B). A sharply decrease of frequency response was observed when A-CdTe probes were injected into the test system in the presence of T-G mismatch mutation DNA strands. (curve c, Fig. 7A). As expected, while the $\mathrm{C}$-CdTe probes were injected into the test system in the present of T-G mismatch mutation DNA strand, a great frequency response shift was observed as well (curve d, Fig. 7A). In contrast, when the T-CdTe probes (curve a, Fig. 7A) or G-CdTe probes (curve b, Fig. 7A) were used, only a small QCM resonance frequency shift was observed. The significant QCM resonance frequency decreases should result from the A-T and C-G specific base pairing and the small frequency shifts should be attributed to the nonspecific adsorption.

The same method was employed to identify A-C mismatch mutation in DNA strand, and the results are shown in Fig. 7B. Obvious frequency decreases were observed during the
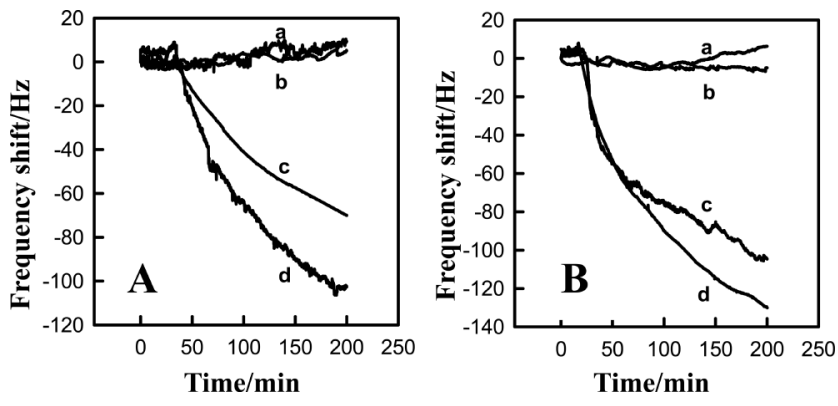

Fig. 7 Frequency change versus time during the hybridization of single base modified CdTe probes with mutation captures DNA. (A) A T-G mismatch is involved. Probes T-CdTe (a), G-CdTe (b), A-CdTe (c) and $\mathrm{C}-\mathrm{CdTe}(\mathrm{d})$ were added to T-G mismatch system, respectively. The mismatch DNA was prepared by the hybridization of biotinylated DNA with target DNA 2 and complementary strand 3. (B) An A-C mismatch is involved. Probes A-CdTe (a), C-CdTe (b), T-CdTe (c) and G-CdTe (d) were added to A-C mismatch system, respectively. The mismatch DNA was prepared by the hybridization of biotinylated DNA with target DNA 1 and complementary strand 4.

hybridization of the A-C mismatch mutation site in the target DNA with T-CdTe (curve $\mathrm{c}$ in Fig. 7B) and G-CdTe probes (curve $\mathrm{d}$ in Fig. 7B). When A-CdTe or C-CdTe probes were used (curve a or b in Fig. 7B), only very small QCM response frequency shifts were obtained. The obvious difference between the response signals enables us to determine a mismatch in a very simple and rapid way.

\section{Conclusions}

In the present study, we have presented a new single base mutation QCM detection method based on gold coated $\mathrm{Fe}_{4} \mathrm{O}_{3}$ nanoparticles and single-base coded CdTe nanoprobes. Compared with conventional detection methods, this new assay has many advantages: (a) high specificity and sensitivity, (b) speedy measurements and low costs, (c) ease and convenience for regenerating the electrodes. Such high specificity and sensitivity also makes the method very useful for the point mutation detection as well as SNP genotyping in genetics. We expect that the proposed point mutation detection method will find wide applications not only in the field of clinical diagnosis of genetic diseases and pharmacogenetics, but in the cancer studies as well.

\section{Acknowledgements}

This work was supported by the National Natural Science Foundation of China (20975037, 21075037, 21145001, 20675030), and Scientific Research Fund of Hunan Provincial Science and Technology Departments (09JJ3019, 07JJ3024).

\section{References}

1. T. Gura, Science, 2001, 293, 593.

2. J. D. Watson and F. H. C. Crick, Nature (London, UK), 1953, 171, 737.

3. K. Kerman, M. Saito, Y. Morita, Y. Takamura, M. Ozsoz, and E. Tamiya, Anal. Chem., 2004, 76, 1877.

4. Y. Zhang, Z. Tang, J. Wang, H. Wu, A. Maham, and Y. Lin, 
Anal. Chem., 2010, 82, 6440.

5. Y. Cheng, Z. Li, B. Du, and X. Zhang, Analyst, 2008, 133, 750.

6. G. Liu, T. M. H. Lee, and J. Wang, J. Am. Chem. Soc., 2004, 127, 38.

7. M. Ye, Y. Zhang, H. Li, Y. Zhang, P. Tan, H. Tang, and S. Yao, Biosens. Bioelectron., 2009, 24, 2339.

8. Y. Fei, X. Y. Jin, Z. S. Wu, S. B. Zhang, G. Shen, and R. Q. Yu, Anal. Chim. Acta, 2011, 691, 95.

9. S. Li, X. Li, J. Zhang, Y. Zhang, J. Han, and L. Jiang, Colloids Surf., A, 2011, 364, 158.

10. J. Wang, P. E. Nielsen, M. Jiang, X. Cai, J. R. Fernandes, D. H. Grant, M. Ozsoz, A. Beglieter, and M. Mowat, Anal. Chem., 1997, 69, 5200.

11. Y. Okahata, M. Kawase, K. Niikura, F. Ohtake, H. Furusawa, and Y. Ebara, Anal. Chem., 1998, 70, 1288.

12. K. Niikura, H. Matsuno, and Y. Okahata, J. Am. Chem. Soc., 1998, 120, 8537.

13. I. Willner, F. Patolsky, Y. Weizmann, and B. Willner, Talanta, 2002, 56, 847.

14. Y. Weizmann, F. Patolsky, and I. Willner, Analyst, 2001, 126, 1502.

15. X. C. Zhou, L. Q. Huang, and S. F. Y. Li, Biosens.
Bioelectron., 2001, 16, 85.

16. F. Caruso D. N. Furlong, K. Niikura, and Y. Okahata, Colloids Surf., B, 1998, 10, 199.

17. J. H. Jang and H. B. Lim, Microchem. J., 2010, 94, 148.

18. G. K. Kouassi and J. Irudayaraj, Anal. Chem., 2006, 78, 3234.

19. A. Son, D. Dosev, M. Nichkova, Z. Ma, I. M. Kennedy, K. M. Scow, and K. R. Hristova, Anal. Biochem., 2007, 370, 186.

20. P. S. Eastman, W. Ruan, M. Doctolero, R. Nuttall, G. de Feo, J. S. Park, J. S. F. Chu, P. Cooke, J. W. Gray, S. Li, and F. F. Chen, Nano Lett., 2006, 6, 1059.

21. H. Zhang, Z. Zhou, B. Yang, and M. Gao, J. Phys. Chem. B, 2002, 107, 8 .

22. J. Xu, Y. Weizmann, N. Krikhely, R. Baron, and I. Willner, Small, 2006, 2, 1178.

23. G. Liu and Y. Lin, J. Am. Chem. Soc., 2007, 129, 10394.

24. Z. Cai, H. Yang, Y. Zhang, and X. Yan, Anal. Chim. Acta, 2006, 559, 234.

25. S. J. Cho, J. C. Idrobo, J. Olamit, K. Liu, N. D. Browning, and S. M. Kauzlarich, Chem. Mater., 2005, 17, 3181.

26. G. Z. Sauerbrey, Z. Phys., 1959, 155, 206. 